\title{
Precipitates with Peculiar Morphology Consisting of a Disk-Shaped Amorphous Core Sandwiched between 14H-Typed Long Period Stacking Order Crystals in a Melt-Quenched $\mathrm{Mg}_{98} \mathrm{Cu}_{1} \mathbf{Y}_{1}$ Alloy
}

\author{
Makoto Matsuura $^{1}$, Kazuya Konno ${ }^{1}$, Mitsuhiko Yoshida ${ }^{1}$, Masahiko Nishijima ${ }^{2}$ and Kenji Hiraga ${ }^{2}$ \\ ${ }^{1}$ Miyagi National College of Technology, Natori 981-1239, Japan \\ ${ }^{2}$ Institute for Materials Research, Tohoku University, Sendai 980-8577, Japan
}

The microstructure of a melt-quenched $\mathrm{Mg}_{98} \mathrm{Cu}_{1} \mathrm{Y}_{1}$ alloy has been studied by high-resolution transmission electron microscopy (HRTEM) and high-angle annular detector dark-field scanning transmission electron microscopy (HAADF-STEM). We have found Cu- and Y-rich precipitates, which are uniformly dispersed in $\mathrm{Mg}$-matrix grains. The precipitates are aligned parallel to the c-plane of the Mg-matrix crystal, and have the peculiar morphology consisting of a disk-shaped amorphous core sandwiched between 14H-typed long period stacking order (LPSO) crystals. A relatively stable supper-cooled liquid phase in an $\mathrm{Mg}-\mathrm{Cu}-\mathrm{Y}$ alloy system, and the formation and growth of the LPSO crystals from the amorphous phase are responsible for the peculiar morphology of the precipitates.

(Received December 22, 2005; Accepted March 9, 2006; Published April 15, 2006)

Keywords: high-resolution transmission electron microscopy, high-angle annular detector dark-field scanning transmission electron microscopy, magnesium-cupper-yttrium, precipitate, long period stacking order, amorphous

\section{Introduction}

The Mg-Cu-Y ternary alloy system is known to exhibit a stable super-cooled liquid state at the concentration around $\mathrm{Mg}_{65} \mathrm{Cu}_{25} \mathrm{Y}_{10}$, which enables to form bulk metallic glass. ${ }^{1,2)}$ In order to know reasons for the stabilization of the supercooled liquid state in this alloy system, it is necessary to study the effects on the structure of $\mathrm{Mg}$ host by the addition of $\mathrm{Cu}$ and Y. For example, how it changes by the single addition of $\mathrm{Cu}$ and the simultaneous addition of $\mathrm{Cu}$ and $\mathrm{Y}$. Therefore, the microstructures of melt-quenched $\mathrm{Mg}_{100-(x+y)} \mathrm{Cu}_{x} \mathrm{Y}_{y}$ alloys have been studied. In the course of the investigation, we have found precipitates aligned parallel to the c-plane of the matrix $\mathrm{Mg}$ crystal in a melt-quenched $\mathrm{Mg}_{98} \mathrm{Cu}_{1} \mathrm{Y}_{1}$ alloy. The precipitates have the peculiar morphology consisting of a disk-shaped amorphous core sandwiched between 14H-typed long period stacking order (LPSO) crystals. In this report, we show the results of the structural studies of the precipitates by HRTEM and HAADF-STEM.

The LPSO phase was found by Kawamura et al. in the rapidly solidified powder metallurgy $\mathrm{Mg}_{98} \mathrm{Zn}_{1} \mathrm{Y}_{2}$ alloy. Afterward the structure details were studied by Luo et al. and it was identified as an 18R-typed LPSO structure. ${ }^{4)}$ This 18Rtyped LPSO structure consists of ABABABCACACABC$\mathrm{BCBC}$ stacking order of close-packed planes, in contrast to AB stacking for the hcp Mg crystal. Such LPSO structure has been found for other concentrations in the $\mathrm{Mg}-\mathrm{Zn}-\mathrm{Y}$ alloy system and also for as-cast $\mathrm{Mg}_{98} \mathrm{Zn}_{1} \mathrm{R}_{2}(\mathrm{R}=\mathrm{Dy}$, Ho and $\mathrm{Er})$ alloys. ${ }^{5)}$ Also, a 14H-typed LPSO phase with an ABACB$\mathrm{CBCBCABAB}$ stacking sequence has been found in the $\mathrm{Mg}$ $\mathrm{Zn}-\mathrm{Y}$ alloy system. ${ }^{6}$ It is interesting to investigate how and why such LPSO structures can develop in the hcp Mg crystal, and to know whether other systems like $\mathrm{Mg}-\mathrm{Cu}-\mathrm{R}$ can form such LPSO structure.

\section{Experimental Procedures}

$\mathrm{Mg}_{98} \mathrm{Cu}_{2}$ and $\mathrm{Mg}_{98} \mathrm{Cu}_{1} \mathrm{Y}_{1}$ alloy samples were prepared by melt spinning technique. $\mathrm{Mg}$ (99.95\%), $\mathrm{Cu}$ (99.99\%) and $\mathrm{Y}$ $(99.5 \%)$ were melted together by induction heating under $0.09 \mathrm{MPa}$ Ar gas in a carbon crucible and were subsequently injected to a rotating $\mathrm{Cu}$ wheel. A quenching from a melt was done with the surface velocity of $42 \mathrm{~m} / \mathrm{s}$. The results of X-ray diffraction using $\mathrm{Cu} K_{\alpha}$ radiation show that very weak peaks of $\mathrm{Mg}_{2} \mathrm{Cu}$ are observed for the $\mathrm{Mg}_{98} \mathrm{Cu}_{2}$ alloy, but not for the $\mathrm{Mg}_{98} \mathrm{Cu}_{1} \mathrm{Y}_{1}$ alloy. Ribbon samples were thinned by grinding and ion milling for TEM observations. HRTEM observations were performed by a $400 \mathrm{kV}$ electron microscope (JEM4000EX) having a resolution of $0.17 \mathrm{~nm}$, and HAADF-STEM images were taken by a $300 \mathrm{kV}$ electron microscope (JEM$3000 \mathrm{~F}$ ) equipped with a field emission gun in the scanning transmission electron microscope mode. In HAADF-STEM observations, a beam probe with a half width of about $0.2 \mathrm{~nm}$ was scanned on samples. Energy dispersive X-ray spectroscopy (EDS) was performed with the JEM-3000F microscope operated at $300 \mathrm{kV}$.

\section{Experimental Results}

Figures 1(a) and (b) show HAADF-STEM images for the $\mathrm{Mg}_{98} \mathrm{Cu}_{2}$ and $\mathrm{Mg}_{98} \mathrm{Cu}_{1} \mathrm{Y}_{1}$ alloys. Bright areas in Fig. 1 indicate $\mathrm{Cu}$ - and/or Y-rich regions. In Fig. 1(a) of the $\mathrm{Mg}_{98} \mathrm{Cu}_{2}$ alloy, $\mathrm{Mg}_{2} \mathrm{Cu}$ crystals are formed as spherical precipitates dispersed in $\mathrm{Mg}$-matrix grains and as layers along grain boundaries. On the other hand, in Fig. 1(b) of the $\mathrm{Mg}_{98} \mathrm{Cu}_{1} \mathrm{Y}_{1}$ alloy, one can see many fine precipitates dispersed with definite directions, which are parallel to the c-plane of the matrix grain, and thin $\mathrm{Cu}$ - and Y-rich layers along grain boundaries. It is worth to notice that the substitution of only 1 at $\%$ Y for $\mathrm{Cu}$ in $\mathrm{Mg}_{98} \mathrm{Cu}_{2}$ dramatically changes the morphology and crystal structure of the precipitates.

Structure details of the precipitates inside grains in the $\mathrm{Mg}_{98} \mathrm{Cu}_{1} \mathrm{Y}_{1}$ alloy have been studied by HRTEM. The images are shown in Figs. 2 and 3. Figure 2 shows that the precipitates have the peculiar morphology; a core part with 

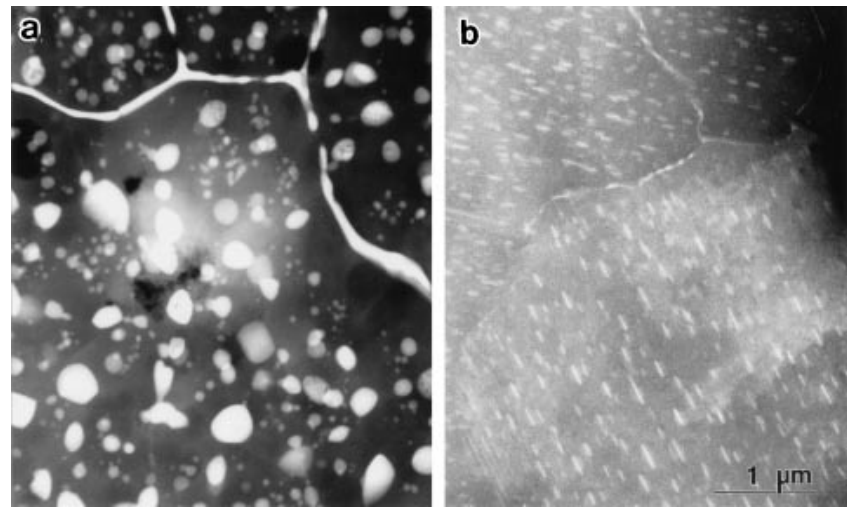

Fig. 1 HAADF-STEM images of melt-quenched $\mathrm{Mg}_{98} \mathrm{Cu}_{2}$ (a) and $\mathrm{Mg}_{98} \mathrm{Cu}_{1} \mathrm{Y}_{1}$ (b) alloys. Bright areas correspond to $\mathrm{Cu}$ and/or Y-rich regions.

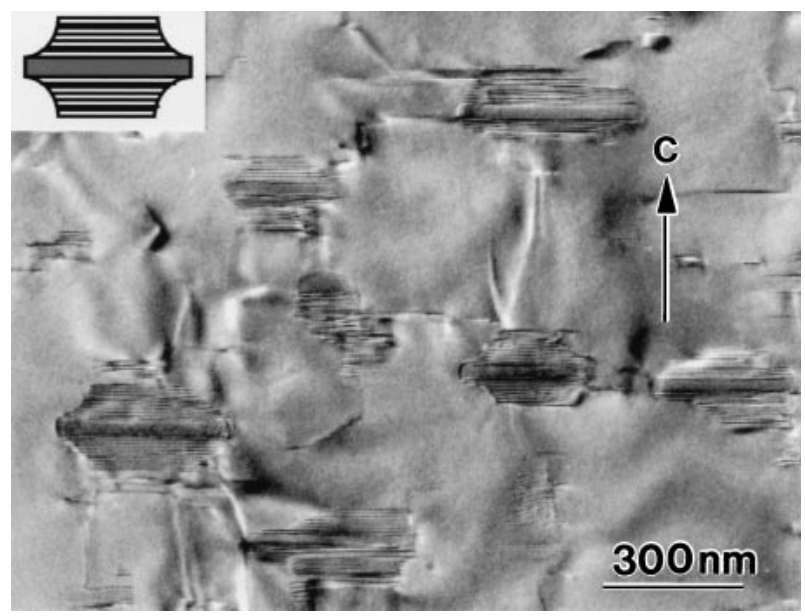

Fig. 2 HRTEM image of precipitates in a Mg-matrix grain in the $\mathrm{Mg}_{98} \mathrm{Cu}_{1} \mathrm{Y}_{1}$ alloy. The c-axis of the Mg-matrix grain is indicated. A schematic drawing showing the morphology of the precipitate is inserted.

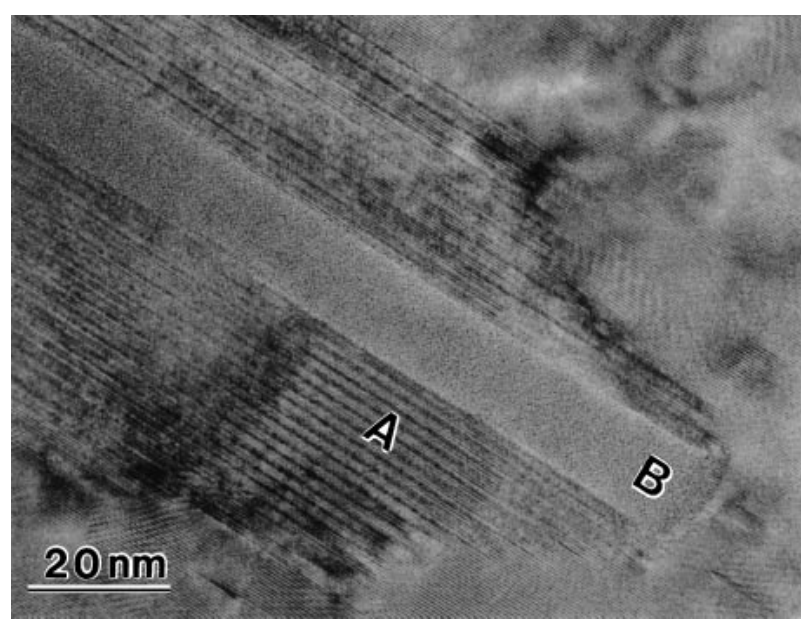

Fig. 3 HRTEM image of a precipitate, showing the morphology consisting of a disk-shaped core sandwiched between two LPSO crystals.

a disk-like shape is sandwiched between two crystals with lattice fringes, as shown by schematic drawing. The disk planes of all precipitates are aligned along the horizontal direction, which is parallel to the c-plane of the hcp $\mathrm{Mg}$

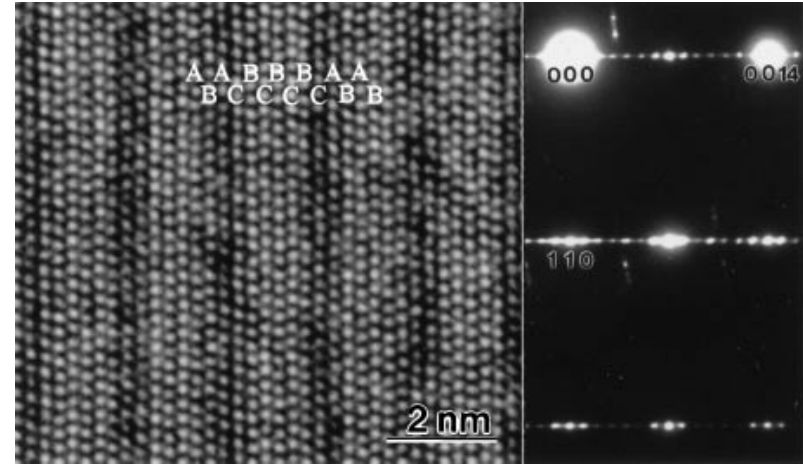

Fig. 4 Enlarged HRTEM image of the part A in Fig. 3 and electron diffraction pattern taken from the part A, showing a 14-typed LPSO structure with an $\mathrm{ABACBCBCBCABAB}$ stacking sequence.

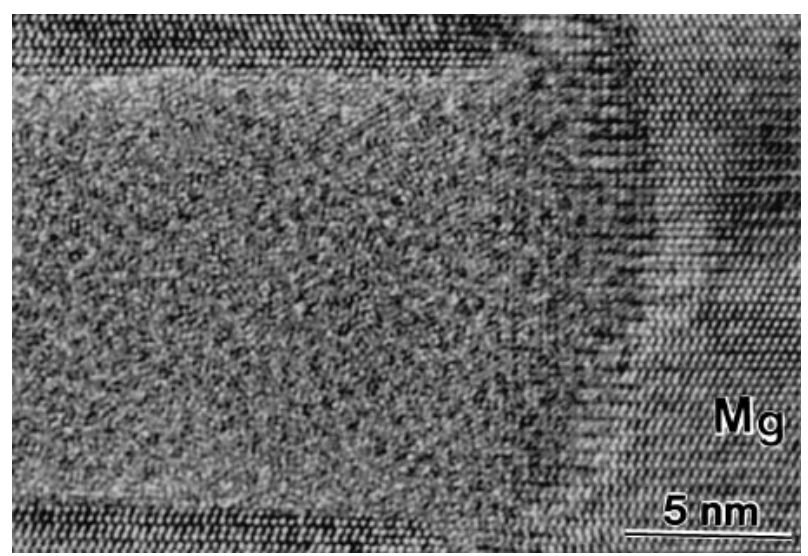

Fig. 5 Enlarged HRTEM image of the part B in Fig. 3, showing an amorphous structure of the disk-shaped core.

crystal. The morphology of the precipitate can be clearly seen in Fig. 3.

Enlarged images of the $\mathrm{A}$ and $\mathrm{B}$ regions in Fig. 3 are shown in Figs. 4 and 5, respectively. The image and electron diffraction pattern of Fig. 4 indicate that the A area is a $14 \mathrm{H}-$ typed LPSO structure with an ABACBCBCBCABAB stacking sequence of close-packed planes. This is the first time to find such 14H-typed LPSO structure in the $\mathrm{Mg}-\mathrm{Cu}-\mathrm{Y}$ system. Figure 5 shows that the core part of the precipitate is an amorphous structure showing a typical granular-like pattern. That is, the amorphous region with a disk-like shape is sandwiched between two 14H-typed LPSO crystals. The amorphous region touches to the LPSO crystals with interfaces of the close-packed plane at the disk plane, whereas it directly contacts with the Mg-matrix crystal at the disk edge.

Compositions of the amorphous and LPSO areas were evaluated by EDS as 67 at $\% \mathrm{Mg}, 28$ at $\% \mathrm{Cu}$ and 5 at $\% \mathrm{Y}$ $\left(\mathrm{Mg}_{67} \mathrm{Cu}_{28} \mathrm{Y}_{5}\right)$ and $80 \mathrm{at} \% \mathrm{Mg}, 15 \mathrm{at} \% \mathrm{Cu}$ and $5 \mathrm{at} \% \mathrm{Y}$ $\left(\mathrm{Mg}_{80} \mathrm{Cu}_{15} \mathrm{Y}_{5}\right)$, respectively. The reported composition of the 14H-typed LPSO in an $\mathrm{Mg}_{97} \mathrm{Zn}_{1} \mathrm{Y}_{2}$ alloy is $\mathrm{Mg}_{87} \mathrm{Zn}_{7} \mathrm{Y}_{6},{ }^{6}$ i.e. the composition of $\mathrm{Zn}$ of the 14H-typed LPSO is about half of $\mathrm{Cu}$ for the present $\mathrm{Mg}_{98} \mathrm{Cu}_{1} \mathrm{Y}_{1}$ alloy.

Figure 6 shows a HAADF-STEM image of a precipitate. $\mathrm{Cu}$ and $\mathrm{Y}$ atoms are homogeneously distributed in the amorphous region, but they are enriched at definite atomic 


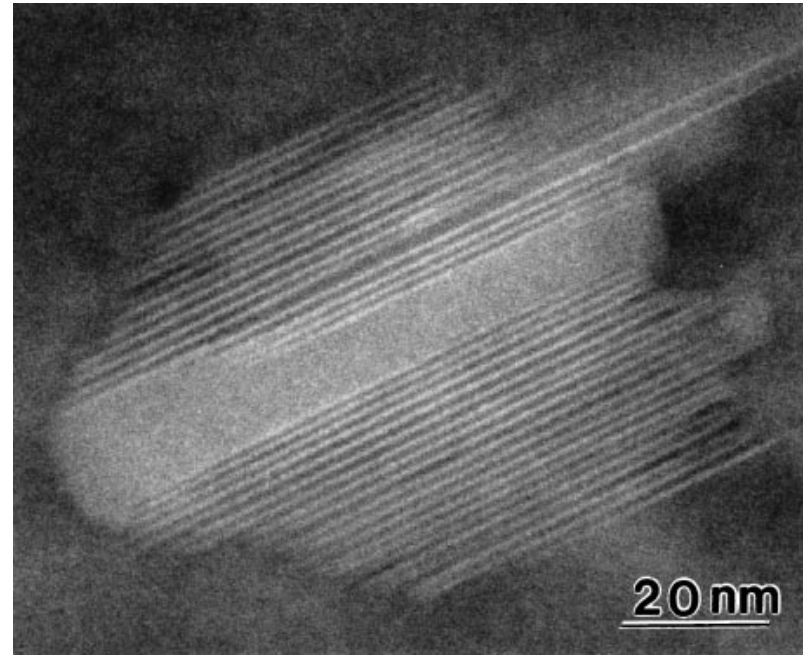

Fig. 6 HAADF-STEM image of a precipitate.

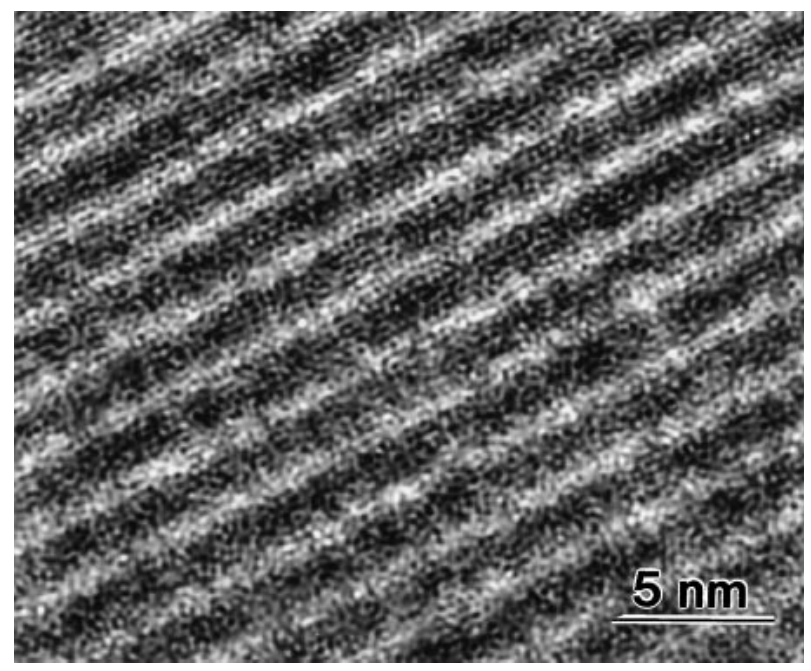

Fig. 7 Atomic-scaled HAADF-STEM image of a LPSO region, showing that $\mathrm{Cu}$ - and $\mathrm{Y}$ atoms occupy two atomic layers across stacking faults.

layers in the LPSO structure, as can be seen as bright lines. An atomic-scaled HAADF-STEM image of the LPSO structure in Fig. 7 shows that $\mathrm{Cu}$ and $\mathrm{Y}$ atoms are enriched at two atomic layers across stacking faults in the $\mathrm{ABA}_{\uparrow} \mathrm{CBCBCBC}_{\uparrow} \mathrm{ABAB}$ stacking sequence of the $14 \mathrm{H}-$ typed LPSO structure, where the arrows show staking faults. Similar result has been found in the LPSO structures in an $\mathrm{Mg}_{97} \mathrm{Zn}_{1} \mathrm{Y}_{2}$ alloy. ${ }^{7)}$ However, in the comparison with the composition of $\mathrm{Mg}_{87} \mathrm{Zn}_{7} \mathrm{Y}_{6}$ for the 14H-typed LPSO phase in the $\mathrm{Mg}-\mathrm{Zn}-\mathrm{Y}$ alloy system, the $\mathrm{Mg}_{80} \mathrm{Cu}_{15} \mathrm{Y}_{5}$ of the LPSO phase in the $\mathrm{Mg}-\mathrm{Cu}-\mathrm{Y}$ alloy system is rather $\mathrm{Cu}$ - and $\mathrm{Y}$-rich composition. If two atomic planes across stacking faults are fully occupied by $\mathrm{Cu}$ and $\mathrm{Y}$ atoms, the composition becomes $\mathrm{Mg}_{5}(\mathrm{Cu}, \mathrm{Y})_{2}$. The composition of $\mathrm{Mg}_{80} \mathrm{Cu}_{15} \mathrm{Y}_{5}$ suggests that two atomic planes across stacking faults are substituted by $\mathrm{Cu}$ and $\mathrm{Y}$ atoms in the ratio of $(\mathrm{Cu}, \mathrm{Y}) / \mathrm{Mg}=0.625$.

In order to understand the formation mechanism of the LPSO crystals from the amorphous phase, we have investigated the morphology at grain boundaries. Figure 8 shows a HAADF-STEM image around a grain boundary. In Fig. 8,

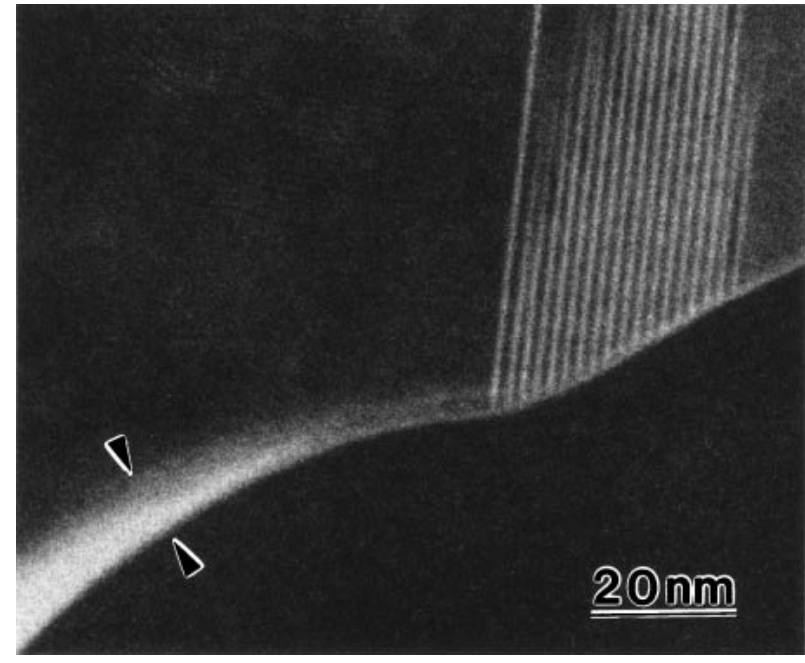

Fig. 8 HAADF-STEM image showing an amorphous layer and LPSO crystal on a grain boundary.

one can see two different parts, i.e. an amorphous layer along the grain boundary, as indicated by a pair of arrowheads, and the LPSO crystal growing from the boundary up to the inside of the Mg-matrix crystal. The observation shows that the LPSO crystals evolve and grow inside the Mg-matrix by consuming the amorphous layer.

\section{Discussion}

The reasons, why and how such precipitates with the peculiar morphology consisting of a disk-shaped amorphous core sandwiched between 14H-typed LPSO crystals are formed in the melt-quenched $\mathrm{Mg}_{98} \mathrm{Cu}_{1} \mathrm{Y}_{1}$ alloy, are the main issue of the present discussion. The precipitates have following characteristic features; 1) a peculiar shape aligned along the c-plane of the hcp Mg-crystal, 2) the amorphous core with a disk-like shape sandwiched between two LPSO crystals, and 3) preferential development of the LPSO crystals along the direction normal to planes of the diskshaped amorphous core and no LPSO crystals at edges of the amorphous core.

The solubility limit of $\mathrm{Cu}$ in the $\mathrm{Mg}$ crystal is very low, i.e. maximum value of 0.013 at\%, whereas that of $\mathrm{Y}$ is about 3 at $\%$ at $840 \mathrm{~K}$ and decreases with decreasing temperature. ${ }^{8)}$ Although there is no information about the solubility limits of $\mathrm{Y}$ and $\mathrm{Cu}$ in the ternary $\mathrm{Mg}-\mathrm{Cu}-\mathrm{Y}$ system, most of $\mathrm{Cu}$ and a part of $\mathrm{Y}$ solutes in the liquid phase are ejected at a solidliquid interface during the rapid solidification process. The $\mathrm{Cu}$ - and $\mathrm{Y}$-concentrated liquids segregate at somewhere inside $\mathrm{Mg}$-crystal grains and also at grain boundaries as $\mathrm{Cu}$ and Y-enriched amorphous phases. A part of the amorphous phase probably transforms to the stable LPSO phase. As previously mentioned, the amorphous and LPSO regions in the precipitates have compositions of $\mathrm{Mg}_{67} \mathrm{Cu}_{28} \mathrm{Y}_{5}$ and $\mathrm{Mg}_{80} \mathrm{Cu}_{15} \mathrm{Y}_{5}$, respectively. The composition $\mathrm{Mg}_{67} \mathrm{Cu}_{28} \mathrm{Y}_{5}$ of the amorphous phase is similar to the $\mathrm{Mg}_{65} \mathrm{Cu}_{25} \mathrm{Y}_{10}$ composition that enables to form bulk metallic glass. ${ }^{1,2)}$ Such a high $\mathrm{Cu}$-rich amorphous phase is probably formed by the transfer of $\mathrm{Cu}$ atoms ejected by the transformation from the primary amorphous phase to the LPSO phase with a 
relatively low $\mathrm{Cu}$-rich composition, and consequently the $\mathrm{Cu}$-rich amorphous phase is stabilized and left as the core of the precipitates.

In the formation process of the LPSO crystals, Y atoms supersaturated in the Mg-crystal phase migrate toward the LPSO phase and assist the growth of the LPSO crystals inside the $\mathrm{Mg}$ grains. The observation shown in Fig. 8 supports the above considerations. In Fig. 8, one can see an amorphous layer with a thickness of about $10 \mathrm{~nm}$ at the grain boundary without any LPSO crystals, and also an LPSO crystal growing inside the Mg-crystal phase from the grain boundary without any amorphous layer. The result of Fig. 8 indicates that the LPSO crystal grows to inside the Mg-grain by eating up the amorphous layer and by the migration of $\mathrm{Y}$ atoms from the Mg-crystal.

The precipitates have a characteristic shape squashed along the c-axis of hcp Mg crystal. This shape is considered to result from primary amorphous particles. Amorphous particles in isotropic crystals have a spherical shape due to surface energy, but those in anisotropic crystals like the hcp $\mathrm{Mg}$ are considered to have the shape that a sphere is squashed along the c-axis and extended parallel to the c-plane of the hcp Mg-crystal. The fast growth of the LPSO crystal along the close-packed plane and slow growth along the direction normal to the close-packed plane from the primary amorphous particles are also responsible to the shape of the precipitates. The feature that the LPSO crystal grows toward the amorphous phase and $\mathrm{Mg}$-crystal can be clearly seen in Fig. 6. In the image, one can see stacking faults terminating in the amorphous phase and growing inside the $\mathrm{Mg}$-matrix.

At the present time, however, we cannot understand why the edges of the disk-shaped amorphous core directly face to the Mg-matrix crystal with no LPSO crystals grown.

\section{Conclusion}

We have studied the microstructure of $\mathrm{Cu}$ - and $\mathrm{Y}$-rich precipitates in a melt-quenched $\mathrm{Mg}_{98} \mathrm{Cu}_{1} \mathrm{Y}_{1}$ alloy. Those precipitates dispersed in Mg-matrix grains are aligned parallel to the c-plane of the Mg-matrix crystal, and have peculiar morphology consisting of a disk-shaped amorphous core sandwiched between 14H-typed LPSO crystals. The amorphous and LPSO phases have compositions of $\mathrm{Mg}_{67} \mathrm{Cu}_{28} \mathrm{Y}_{5}$ and $\mathrm{Mg}_{80} \mathrm{Cu}_{15} \mathrm{Y}_{5}$, respectively. The $\mathrm{Cu}$ and $\mathrm{Y}$ atoms are homogeneously distributed in the amorphous phase, but they are located at two specific atomic layers across stacking faults in the $14 \mathrm{H}$-typed LPSO crystals. The crystal growth of LPSO crystals from the amorphous phase and a relatively stable supper-cooled liquid phase at around $\mathrm{Mg}_{65} \mathrm{Cu}_{25} \mathrm{Y}_{10}$ alloys are responsible for the formation of the precipitates with such peculiar morphology.

\section{Acknowledgements}

This works is financially supported by the Grant-in-Aid for Scientific Research on Priority Areas on "Materials Science of Bulk Metallic Glasses" and also supported by the "Nanotechnology Support Project" of the Ministry of Education, Culture, Sports, Science and Technology (MEXT), Japan.

\section{REFERENCES}

1) A. Inoue, A. Kato, T. Zhang, S. G. Kim and T. Masumoto: Mater. Trans. JIM 32 (1991) 609-616.

2) A. Inoue, T. Nakamura, N. Nishiyama and T. Masumoto: Mater. Trans. JIM 33 (1992) 937-945.

3) Y. Kawamura, K. Hayashi, A. Inoue and T. Masumoto: Mater. Trans. 42 (2001) 1172-1176.

4) Z. P. Luo and S. Q. Zhang: J. Mater. Sci. Lett. 19 (2000) 813-815.

5) S. Yoshimoto, M. Yamasaki and Y. Kawamura: Mater. Trans, in preparation.

6) T. Itoi, T. Semiya, Y. Kawamura and M. Hirohashi: Scripta Mater. 51 (2004) 107-111.

7) E. Abe, Y. Kawamura, K. Hayashi and A. Inoue: Acta Mater. 50 (2002) 3845-3855.

8) Binary Alloy Phase Diagrams, ed. by T. B. Massalski (ASM international, 1986) Vol. 2 and 3. 